ein festeres und dunbleres Mark und ein stärlierer, mohr holsiger Hern. Auch läfst sich dieser leichter rom Marke entblofsen und dieses schmeckt eclielerregend, whihrend Nanary einen angenehmen Geschmack besitzt.

Die letzte Parthie Nanary wurde in I.ondon um 3 Schillinge und 6 Pence, also un ohngefähr $24.6 \mathrm{kr}$. im Grofsen verhauft. Bei einer newen Antionft werde ich eiwas davon bexiehen, damit genauere Versuche, sowohl in chemischer als auch therapeutischer Hinsicht; damit angestellt werden Hönnen.

\title{
Versuche uber mehre Theile der Sophora japonica
}

r $0 \mathrm{n}$

Fleurot zu Dijon.

(Aus\%. a. d. Journ. de Phitrm., X1X. 5.o $4.6 j-$ )

Nach dieser. Untersuchung ist der Purgiren bewirkende Bestandtheil der Sophora eine Substanz, die Fleurot fiis Cathurtin hält und die in der Rinde, dem Holze, den Blättern und den Früchten dieser Jeguminose enthalten ist, sugleich mil einem riechenden Princip, einer gelben färbenden Materie, Eiweifs, Stärkmehl, Gummi, Schleimzucker, eine dem Hautschuk ähnliche Substaaz, ëpfelsanren Kalk und roehre Mineralsalze. Ga rot bemerlit dazu, dafs nach dem ron Fleurot befolgten Verfabren er liein roines Produkt als Cathartin habe erhalten können und er sich darauf stütze, dals die extralitive Materie Cathartin sey, weil sie ge $\mathbf{n}$ ?agentien fast wie das Cathartin der Senna sich verhaltu; die Wirhung dieser Materie auf den Organisnus ist auch nicht untersucht worden.

Sie soll in dem Holze, den Blättern und den Frïcbten 
entbalten seyn, obgleich die Pulpa der Friichte nach 1) evandolle herb und adstringirend ist.

Wenn in China schon die Ausdünstungen dos Baumes hinreichen, um die damit beschäftigten Einwohner zum Purgiren za veranlossen, so ist es augenscheinlich, dafs seit 86 Jahren, wo dieser Baun nach Frankreich hat: er diese energischen Eigenschaften verioren hat, weil Fleurot den Ausdinstungen der verschiedenen Theile, welche er der Analyse unterwarf, ohne Nachtheil sich aussetzen konnte. Daraus Hann man aber nicht schliefsen, dafs die heftigen Wirkungen wolche man von der Sophora beobaclitet hat, von einigen Partikein, die Cathartin enthalten und in den Mngen gelangten, berrührten, und nicbt von cinem flüchtigen Princine. Jebrigens dürfte es schwierig seyn vorauszubestinmen, welche die wirksamen Stoffe eines Baumes seyn hörnen, der in Japan natürlich wächst, nach den Resultaten, die man bei de: Untersuchung eises Individuums derselben Epecies erhal. ten hat, welches aus dem Samentorn in unserem gemäfsigten Llima gezogen wurde und seit 86 Jaliren darin vegetirte.

Seite 657 des Journ. de Pharma kömmt Fleurot auf diese Untersuchung zurück. Die von ihr Cathartin benannte Substanz habe alle chemischen und phydischen Figenschaften des von Lassaigne und $F$ eneulle so genanaten Stoffos gezeigt, und deshalb habe er ihr auch denselben Namen bei. gelegt, und os zudem auch mit der Natur übereinstimme, in der Sophora eine furgirend wirkende Substanz anzutreffen, die der der andern purgirend wirker.jeo Pfianzen derrelben Familie analog sey.

Ga rot hat die Quelle nielut angegeben, aus welcher er die Bemerkungen über die Wirkung der Sophora in China schöplte. Aber an Bäunen, welche in Frabletich waclsen, hat man tie purgirenden Eigenschuften der Sopthora erhanmt, und die purrgirande Eigenschaft des Holzes der Sophora ts 
eine fast allgemein bekannte Thatsache, besonders bei Personen, die dasselbe zu Drechslerarbeiten gebrauchen and den Ausdünstungen des Holzes demzufolge mebr ausgesetzt sind als andere Personen. Im botanischen Garten findet sich unter einem schönen Baume von Sophora ein Brunnen, and der Gärtner ist verpflichtet, zar Zeit wenn die Blüthen und Blätter abfallen, die Oeffnung des Brunnens sorgfältig zo bedecken, weil er die Erfahrung erlangt hat, dafs das Wercer zn diesen beiden Epochen, so gesund wie es sonst ist, pargirend wirkt.

Die Sophora japonica ist keinesweges ein bei uns seltener Baum; seit langer Zeit schon ist er eine Zierde der rreisten Parks und Lustgärten. Es ist wahrscheinlich, dafs er wegen seines schnellen Wachsthums and seiner Eigenschaften einst als eine Art Forstbaum wird kultivirt werden können, da er die stärksten Winter unseres Klimas so gut erträgt als ansere einheimischen Bäume.

\section{Ueber Melia sempervirens, die Lilas der Antillen}

ron

Ricord-Madianna.

(Auszug aus dem Journal de Pharmacie XIX, 560.)

Mit dem Namen Melia bezeicbneten Hippolrates und Theophrast die Esche. Die Lilas der Antilien gehört zar Familie der Meliaceen. Die $\mathbf{W u r z e l n}$ und die Früchte dieses schönen in Syrien, Persien und Ostindien ursprünglichen Strauchs werden auf Guadeloupe und mehren andern Inseln für ein Gift gebalten. Wahrscheinlich hommt dieses daher, dafs man die Melia sempervirens nach einigen Botanikern nur 